\title{
Methods to Study PAMP-Triggered Immunity Using Tomato and Nicotiana benthamiana
}

\author{
Hanh P. Nguyen, ${ }^{1,2}$ Suma Chakravarthy, ${ }^{1,3}$ André C. Velásquez, ${ }^{1,3}$ Heather L. McLane, ${ }^{1}$ Lirong Zeng, ${ }^{1,4}$ \\ Hitoshi Nakayashiki, ${ }^{5}$ Duck-Hwan Park, ${ }^{3}$ Alan Collmer, ${ }^{3}$ and Gregory B. Martin ${ }^{1,3}$ \\ ${ }^{1}$ Boyce Thompson Institute for Plant Research, Ithaca, NY, U.S.A.; ${ }^{2}$ Department of Plant Biology, Cornell University, Ithaca, \\ NY, U.S.A.; ${ }^{3}$ Department of Plant Pathology and Plant-Microbe Biology, Cornell University, Ithaca, NY, U.S.A.; ${ }^{4}$ Biology \\ Department, University of Arkansas at Little Rock, Little Rock, AR, U.S.A.; ${ }^{5}$ Laboratory of Plant Pathology, Faculty of \\ Agriculture. Kobe University, 1-1, Rokkodai-cho, Nadu-ku, Kobe 657-8501, Japan
}

Submitted 16 February 2010. Accepted 30 March 2010.

Understanding the molecular basis of plant responses to pathogen-associated molecular patterns (PAMPs) is an active area of research in the field of plant-microbe interactions. A growing number of plant genes involved in various steps of PAMP-triggered immunity (PTI) pathways and microbial factors involved in the elicitation or suppression of PTI have been identified. These studies have largely relied on Arabidopsis thaliana and, therefore, most of the PTI assays have been developed and optimized for that model plant system. Although PTI is a conserved feature among plants, the response spectra vary across different species. Thus, there is a need for robust PTI assays in other pathosystems, such as those involving Solanaceae plantpathogen interactions, which include many economically important plants and their diseases. We have optimized molecular, cellular, and whole-plant methods to measure PTI responses in two widely studied solanaceous species, tomato (Solanum lycopersicum) and Nicotiana benthamiana. Here, we provide detailed protocols for measuring various PTI-associated phenotypes, including bacterial populations after pretreatment of leaves with PAMPs, induction of reporter genes, callose deposition, activation of mitogenactivated protein kinases, and a luciferase-based reporter system. These methods will facilitate limited genetic screens and detailed characterization of potential PTI-related genes in model and economically important Solanaceae spp.-pathogen interactions.

In recent years, many important discoveries have advanced our understanding of plant defenses that are activated when the host plant first senses the presence of a potential pathogen. These early host defenses involve recognition of conserved features of microbes, including flagellin, the major component of bacterial flagella; peptidoglycan (PGN) and chitin, components of the pathogen cell wall; and elongation factor Tu (EFTu) (Boller and Felix 2009). Collectively, these microbial

H. P. Nguyen and S. Chakravarthy contributed equally to this work and are considered co-first authors.

Corresponding author: G. B. Martin; Telephone: (607) 254 1208; Fax: (607) 255 6695; E-mail: gbm7@ cornell.edu

* The $\boldsymbol{e}$-Xtra logo stands for "electronic extra" and indicates that a supplemental table is published online. elicitors are termed pathogen- or microbe-associated molecular patterns (PAMPs or MAMPs). Similar to the Toll-like innate immune signaling pathways characterized in animals, in plants, PAMPs are perceived by pattern recognition receptors (PRR), which trigger a variety of downstream responses, including a calcium burst, activation of mitogen-activated protein kinase (MAPK) cascades, production of reactive oxygen species (ROS), expression of numerous defense-associated genes, production of ethylene, and callose deposition at the cell wall (Asai et al. 2002; Ausubel 2005; Boller and Felix 2009). This first line of defense, termed PAMP-triggered immunity (PTI), acts to inhibit pathogen growth. Current knowledge of PTI is mostly derived from studies performed with Arabidopsis thaliana. For example, the two best-characterized PRR, FLS2 and EFR, receptors of flagellin and EF-Tu, respectively, were identified and characterized in Arabidopsis (GomezGomez and Boller 2000; Zipfel et al. 2006). Two other Arabidopsis protein kinases, BAK1 and BIK1, have been found to be involved in signaling associated with PAMP receptors (Chinchilla et al. 2006; Heese et al. 2007; Lu et al. 2010; Shan et al. 2008; Zhang et al. 2010).

Although PTI appears to be conserved across the plant kingdom, the specific responses and underlying molecular mechanisms may vary in different species. For instance, members of both the Brassicaceae and Solanaceae families perceive flagellin; however, they vary in their sensitivity to different peptides of the protein. Tomato, for example, recognizes a 15amino-acid flagellin peptide from Escherichia coli whereas Arabidopsis does not (Felix et al. 1999; Meindl et al. 2000). Perception of bacterial EF-Tu appears to be conserved in the Brassicaceae family but has not been identified in any Solanaceae spp. examined (Kunze et al. 2004). Differences have been observed in PTI against Pseudomonas syringae pv. tomato DC3000 between Arabidopsis and N. benthamiana, including weaker growth of a DC3000 type III secretion mutant in Arabidopsis, possibly due to differences in PAMP perception between the two species (Hann and Rathjen 2007). These differences indicate that the study of PTI in diverse plant species will be important for a comprehensive understanding of the molecular basis of this important host defense system.

The majority of assays for investigating PTI in whole plants, protoplasts, or cell-culture systems have been developed and standardized for Arabidopsis. These assays include the detection or quantification of calcium production, ROS production, activation of MAPK, induction of defense-responsive genes, and cal- 
lose deposition (Chinchilla et al. 2006; Hauck et al. 2003; He et al. 2006; Zipfel et al. 2004). A few assays have been developed or optimized for $N$. benthamiana such as PTI-mediated suppression of host cell death, staining to detect PTI-associated vascular constriction, callose deposition, calcium burst, ROS, and nitric oxide production (Asai et al. 2008; Chakravarthy et al. 2009; Hann and Rathjen 2007; Heese et al. 2007; Kvitko et al. 2009; Oh and Collmer 2005; Oh et al. 2010). Some assays are readily transferable to other plant species whereas others require significant optimization due to differences in the host response, leaf morphology, or the age, size, and growth conditions of plants that are most conducive for the assay.

We recognized a particular need for robust PTI assays for studying the interactions between model species in the Solana ceae family and their microbial pathogens. This plant family contains approximately 100 genera and more than 2,500 species, including economically important crops such as potato (Solanum tuberosum), tomato (S. lycopersicum), eggplant ( $S$. melongena), pepper (Capsicum spp.), and tobacco (Nicotiana spp.). It is the third most valuable crop family in the world and the most valuable among vegetable crops (Olmstead et al. 2008). Solanaceous plants, such as tomato and $N$. benthamiana, also serve as important model systems for understanding plant immunity at both the organismal and molecular level. The advantages of these model systems include the availability of vast natural variation in the form of wild species, the large number of important and diverse pathogens that attack them, and their amenability to Agrobacterium-mediated transformation and virus-induced gene silencing (VIGS) (Goodin et al. 2008).

Here, we present detailed protocols we have either optimized based on existing PTI assays or developed ourselves for molecular, cellular, and whole-plant methods to measure PTI responses in tomato and $N$. benthamiana. These methods will hopefully aid in the effort to characterize potential PTI-related genes and facilitate the study of plant innate immunity in the economically important interactions between solanaceous plants and their pathogens.

\section{RESULTS AND DISCUSSION}

Preinoculation of $N$. benthamiana leaves with a nonpathogen to induce PTI and enhance differences in bacterial growth between wild-type and PTI-compromised plants.

One of the most convincing forms of evidence to support a role in PTI of a given host gene is to discover an enhancement of bacterial growth in plants that are compromised for expression of the gene compared with wild-type plants. However, in most cases, such differences in bacterial growth are extremely small and special conditions are required for their detection. For instance, an increase in growth of $P$. syringae pv. tomato DC3000 in Arabidopsis plants with a mutation in the flagellin receptor FLS2 compared with wild-type plants was only detectable when plants were spray inoculated and younger leaves were assayed (Zipfel et al. 2004).

It has been shown previously in $N$. benthamiana that preinoculation of a leaf with a nonpathogen followed several hours later by inoculation with a virulent or avirulent bacterium abolishes or significantly delays host cell death associated with disease or the hypersensitive response (HR), respectively (Klement et al. 2003; Oh and Collmer 2005; Oh et al. 2010). We have also shown recently that $N$. benthamiana plants silenced for $F l s 2$ are specifically compromised in their response to flg22 using this cell-death-based PTI assay (Chakravarthy et al. 2010). Therefore, we tested whether preinduction of PTI by a nonpathogen prior to inoculation with pathogenic bacteria would enhance the bacterial growth dif- ference between PTI-compromised and control plants. $N$. benthamiana leaves silenced or not for Fls2 were syringe infiltrated with either $10 \mathrm{mM} \mathrm{MgCl} 2$ alone or with the nonpathogenic saprophyte $P$. fluorescens 55 at $10^{9} \mathrm{CFU} / \mathrm{ml}$. Seven hours later, the plants were syringe infiltrated with the

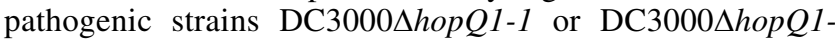
$1 / \triangle a v r P t o / \triangle a v r P t o B$ at a low titer $\left(2 \times 10^{5} \mathrm{CFU} / \mathrm{ml}\right)$. DC3000 $\Delta$ hopQ1-1 lacks the major effector (HopQ1-1) that is recognized by $N$. benthamiana, making it pathogenic on this plant species (Wei et al. 2007), whereas DC3000 4 hopQ1$1 / \Delta a v r P t o / \triangle a v r P t o B$ lacks two additional effectors that are required for full virulence (Kvitko et al. 2009). In plants pretreated with only $\mathrm{MgCl}_{2}$, we were unable to detect any population difference for either $P$. syringae pv. tomato strain in Fls2-silenced compared with empty-vector control plants (Fig. 1). However, when leaf tissue was pretreated with $P$. fluorescens, we observed a statistically significant increase in the population of both pathogenic bacteria in $F l s 2$-silenced plants compared with control plants (Fig. 1). The population

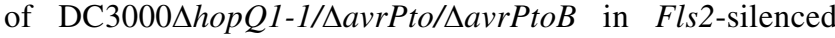
plants was approximately 100 -fold more than in the empty vector control plants three and one-half days postinoculation (Fig. 1A). The population difference of DC3000 4 hopQ1-1 in the silenced plants compared with the control plants, albeit smaller (sixfold), was still statistically significant (Fig. 1B). The smaller growth difference observed with the DC3000 $\triangle h o p Q 1-1$ strain is due to the presence of the AvrPto/ AvrPtoB effectors which are known to be strong suppressors of PTI (Lin and Martin 2005; He et al. 2006; Shan et al. 2008). Therefore, prior induction of PTI with a live nonpathogen effectively enhances the difference in bacterial growth between PTI-compromised plants and control plants, which could otherwise not be detected.

\section{Preinduction of PTI in tomato leaves by using individual PAMPs for inhibition of pathogenic bacterial growth.}

Pretreatment of Arabidopsis with PAMPs such as flg22, elf18, and lipopolysaccharide (LPS) induces PTI, which effectively restricts the growth of pathogenic bacteria inoculated subsequently (Kunze et al. 2004; Mishina and Zeier 2007; Newman et al. 2002). We tested the effectiveness in tomato leaves of preinduction of PTI on bacterial growth inhibition using two PAMPs, PGN (from Staphylococcus aureus) and flg22. Tomato plants pretreated with $1 \mu \mathrm{M}$ flg22 $12 \mathrm{~h}$ prior to bacterial inoculation supported a population of DC3000 $\Delta a v r P t o / \Delta a v r P t o B$ that was significantly lower compared with plants pretreated with buffer only at both 2 and 4 days after inoculation (Fig. 2A). Pretreatment with PGN (100 $\mu \mathrm{g} / \mathrm{ml}$ ) caused a statistically significant reduction of $P$. syringae pv. tomato growth compared with the buffer-treated control plants at 4 days postinoculation (Fig. 2A). Although PGN has been reported to act as a PAMP in plants (Gust et al. 2007; Erbs et al. 2008), this appears to be the first report that pretreatment with PGN can restrict bacterial growth in plants. We note, however, that it is possible this commercial PGN preparation contains other contaminating PAMPs in addition to PGN. Previously, we counted the number of necrotic lesions (specks) in a defined leaf area as another measure of bacterial virulence and host immunity (Lin and Martin 2005). By using that approach, we observed significantly fewer specks 4 days after pathogen inoculation on plants pretreated with either PGN or flg22 compared with buffer-pretreated leaves (Fig. 2B and C). Together, these methods will be useful in tomato for demonstrating the effect on bacterial growth of specific PAMPs and in evaluating the effect of knocking down the expression of host genes putatively involved in PTI. 

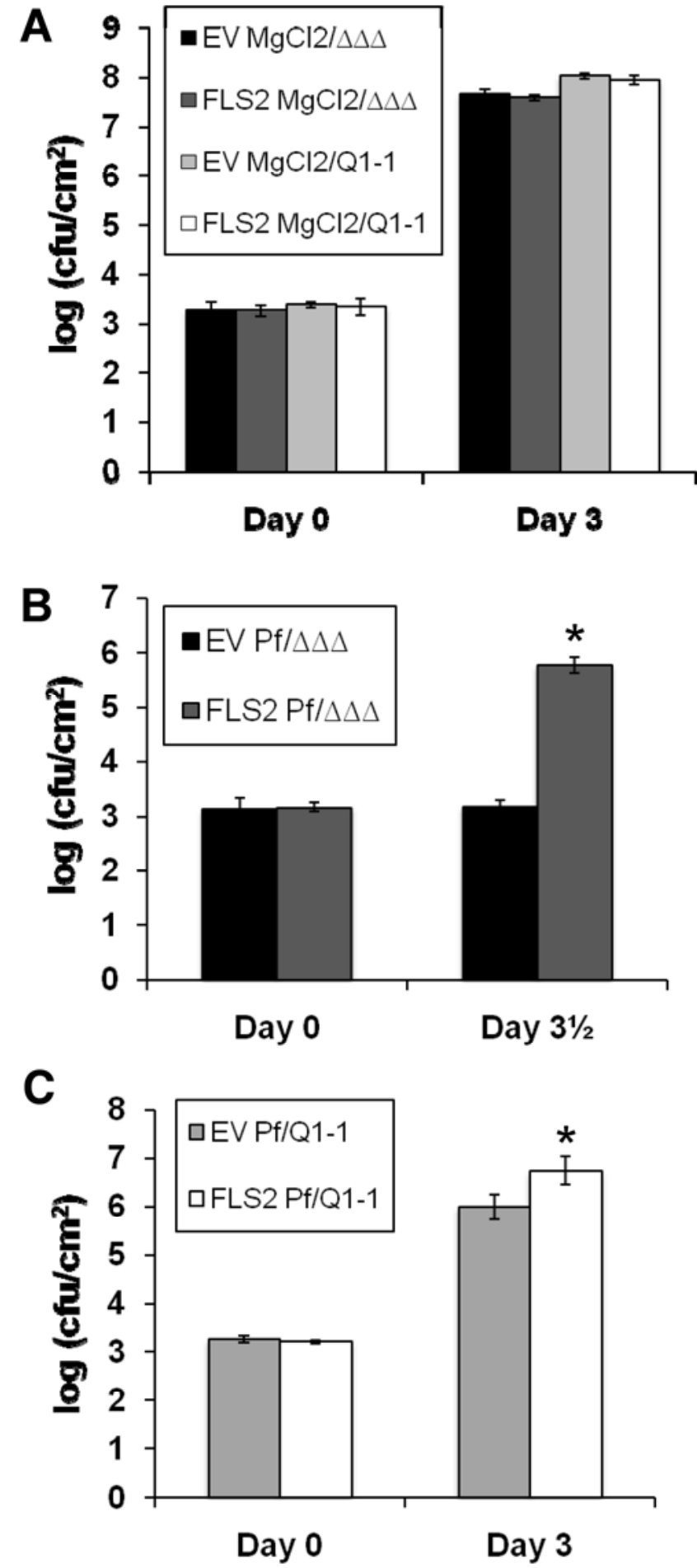

Fig. 1. Pretreatment of plants with a nonpathogenic bacterium enhances the difference observed in pathogenic bacterial populations in Nicotiana benthamiana plants compromised for pathogen-associated molecular pat-

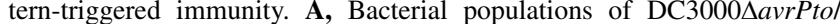
$\Delta a v r P t o B / \Delta h o p Q 1-1(\Delta \Delta \Delta)$ or DC3000 $4 h o p Q 1-1$ (Q1-1) in Fls2-silenced or nonsilenced control plants that were infiltrated with $10 \mathrm{mM} \mathrm{MgCl} 27 \mathrm{~h}$ before inoculation with the pathogenic bacteria $\left(2 \times 10^{5} \mathrm{CFU} / \mathrm{ml}\right)$. B, Bac-

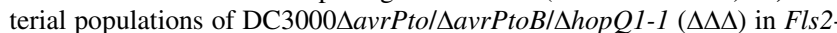
silenced or nonsilenced control plants that were inoculated with Pseudomonas fluorescens 55 at $1 \times 10^{9} \mathrm{CFU} / \mathrm{ml} 7 \mathrm{~h}$ before inoculation with the DC3000 strain at $2 \times 10^{5} \mathrm{CFU} / \mathrm{ml}$. C, Bacterial populations of DC3000 $\Delta$ hopQ1-1 (Q1-1) in Fls2-silenced or nonsilenced plants that were inoculated with $P$. fluorescens 55 at $1 \times 10^{9} \mathrm{CFU} / \mathrm{ml} 7 \mathrm{~h}$ before inoculation with the pathogenic bacteria at $2 \times 10^{5} \mathrm{CFU} / \mathrm{ml}$. Error bars in A, B, and C indicate \pm standard error $(n=4)$. Significantly different populations based on a pairwise Student's $t$ test $(P \leq 0.05)$ are indicated with an asterisk.

\section{Development of reporter genes}

for assaying PTI activation in tomato and $N$. benthamiana.

Gene expression profiling studies of Arabidopsis cell cultures and seedlings treated with flg22 have revealed a large number of genes that are rapidly induced by this PAMP (Navarro et al. 2004). These genes encompass a wide range of functional classes, including receptor-like kinases, transcription factors, and genes involved in protein turnover (Navarro et al. 2004). Similar studies using other PAMP treatments revealed that there is a high degree of similarity in transcrip-
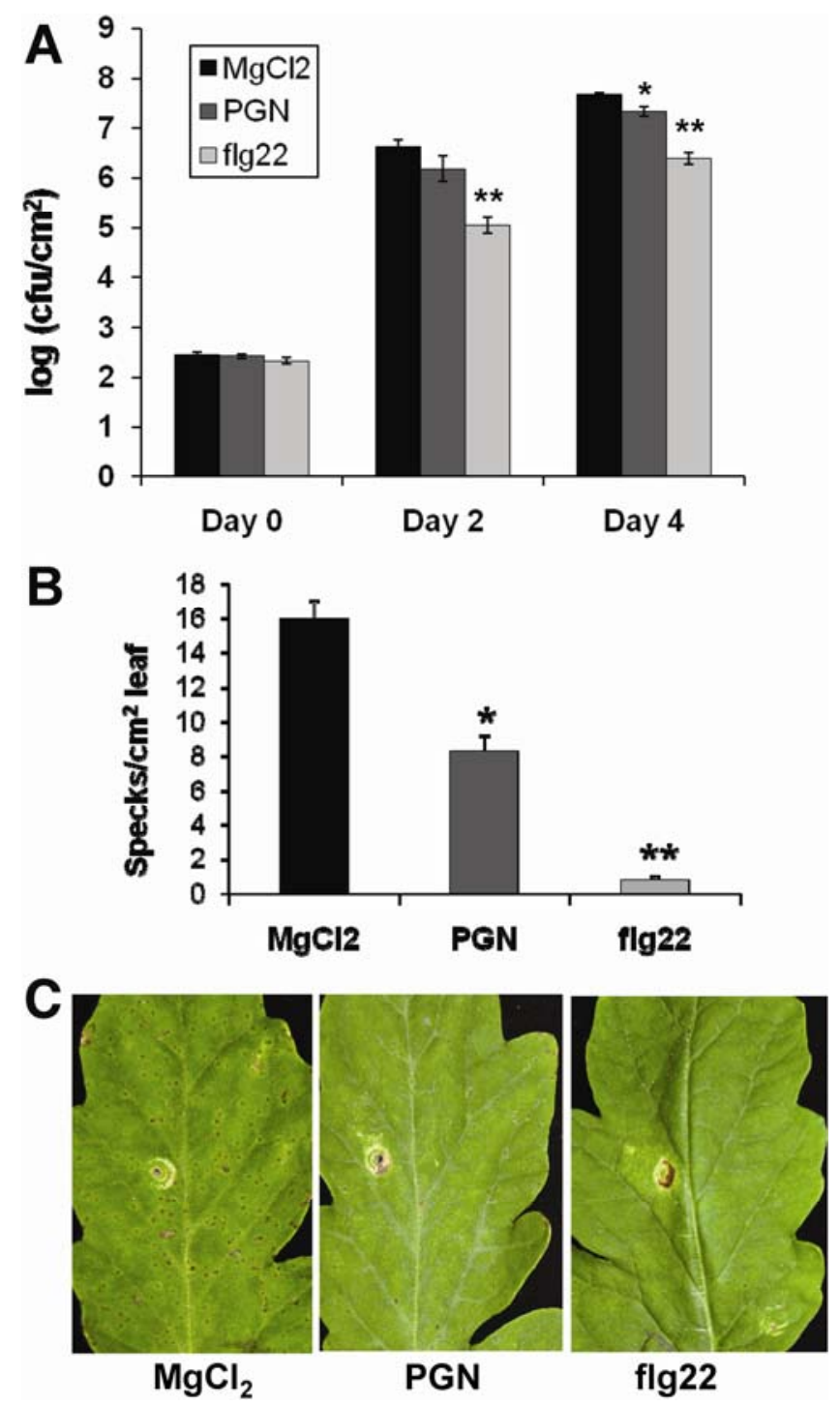

Fig. 2. Preinduction of pathogen-associated molecular pattern (PAMP)triggered immunity by purified PAMPs inhibits the growth and disease symptoms of pathogenic bacteria in tomato leaves. A, Bacterial growth assay on tomato plants (Rio Grande-prf3) pretreated with $1 \mu \mathrm{M}$ flg22, peptidoglycan (PGN) at $100 \mu \mathrm{g} / \mathrm{ml}$, or buffer control $\left(10 \mathrm{mM} \mathrm{MgCl}_{2}\right.$ ) by sy-

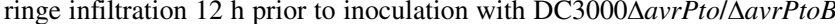
at $10^{4} \mathrm{CFU} / \mathrm{ml}$ by vacuum infiltration. Bacterial populations were measured at day 0,2 , and 4 postinoculation. Significantly different population of bacteria compared with the buffer control based on a pairwise Student's $t$ test is indicated with either one or two asterisks (* and ** indicate $P \leq$ 0.05 and 0.001 , respectively; $n=4$ ). B, Specks were counted using Adobe Photoshop CS4. Significantly different numbers of specks per leaf area compared with the buffer control based on a pairwise Student's $t$ test are indicated with either one or two asterisks (* and ** indicate $P \leq 0.05$ and 0.001 , respectively; $n=6$ ). Error bars in both A and B indicate \pm standard error. C, Photographs of representative leaves from the same experiment as A, 4 days postinoculation. More specks are observable on the $\mathrm{MgCl}_{2}$ control than with PAMP pretreatment. 
tional changes that occur in response to different PAMPs such as elf26, flg22, and PGN, which indicates that some of these differentially expressed genes might be useful as reporters for PTI induction (Gust et al. 2007; Zipfel et al. 2006). In fact, recent studies with Arabidopsis have effectively used expression of certain genes as reporters for PTI in protoplast systems and plant tissues (Shan et al. 2008).

In order to optimize reporter genes for PTI in tomato, we used quantitative reverse-transcriptase polymerase chain reaction (qRT-PCR) to examine the expression in leaves of 26 genes in response to inoculation with the type III secretion mutant $\mathrm{DC} 3000 \Delta h r c Q_{\mathrm{b}} R S T U$ (referred to hereafter as DC3000 $\Delta h r c Q U$ ) (Supplementary Table S1). The genes tested were either tomato homologs of Arabidopsis genes known to be induced by PAMPs (18 genes) or tomato genes known to be induced in response to virulent or avirulent pathogens (8 genes) (Mayrose et al. 2006; Navarro et al. 2004; Thara et al. 1999). Some of these genes were used previously as markers for PTI in the interaction of
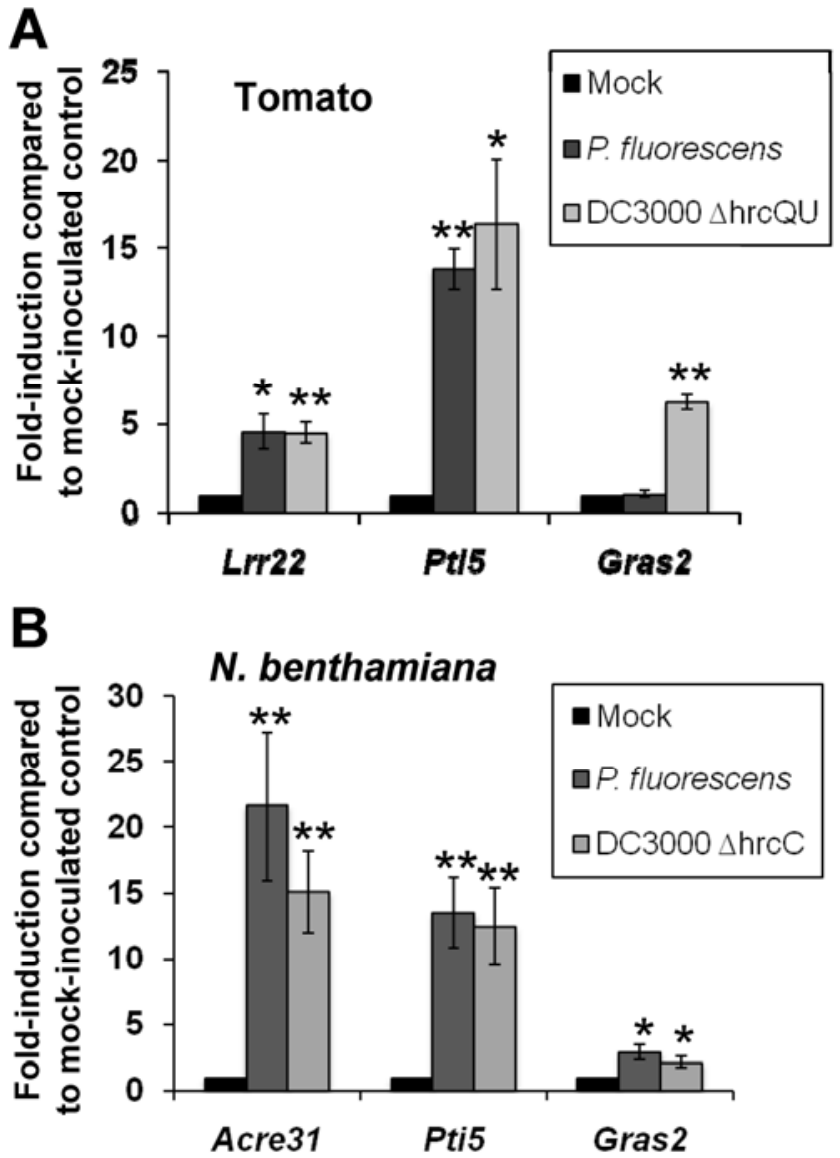

Fig. 3. Induction of reporter genes upon pathogen-associated molecular pattern (PAMP)-triggered immunity activation in tomato and Nicotiana benthamiana. A, Expression of reporter genes Gras2, Lrr22, and Pti5 in tomato (Rio Grande-prf3) leaves $6 \mathrm{~h}$ after inoculation with the nonpathogenic bacterium Pseudomonas fluorescens or DC3000 $\mathrm{hrc} Q U\left(10^{9}\right.$ or $2 \times$ $10^{8} \mathrm{CFU} / \mathrm{ml}$, respectively). Fold-induction levels compared with mockinoculated samples, considered as 1 , are shown. Data presented are the average of values from three plants (three biological replicates with three technical replicates of each) \pm standard error (SE). B, Expression of reporter genes Acre31, Pti5, and Gras 2 in N. benthamiana leaves $6 \mathrm{~h}$ after inoculation with the nonpathogenic bacterium $P$. fluorescens or DC3000 $\operatorname{hrcC}\left(1 \times 10^{9}\right.$ or $2 \times 10^{8} \mathrm{CFU} / \mathrm{ml}$, respectively). Fold-induction levels compared with mock-inoculated samples, considered as 1 , are shown. Data presented are the average of values from five plants (five biological replicates with three technical replicates of each) \pm SE. Significantly different induction levels are indicated with one or two asterisks (* and ** indicate $P \leq 0.05$ and 0.001 , respectively). tomato cv. VF36 with Xanthomonas campestris pv. vesicatoria (Kim et al. 2009). For each gene, the calculated efficiency for primer pairs was $>1.8$ and product size was $\leq 150$ bp (Udvardi et al. 2008). Melting curve analysis was performed at the end of each run to ensure that unique products were obtained. Expression of three of the tomato genes (SlLrr22, SlGras2, and SlPti5) was induced significantly upon inoculation with the nonpathogen $P$. fluorescens or the DC3000 4 hrcQU mutant (Fig. 3A). SlWrky28 was also significantly induced in similar experiments (data not shown) (Kim et al. 2009). SlPti5 expression, in particular, was markedly enhanced during either $P$. fluorescens or DC3000 $4 h r c Q U$-induced PTI, with its expression being $>15$-fold over that of mock-inoculated leaves (Fig. 3A).

We also optimized reporter genes for use in $N$. benthamiana. In this case, qRT-PCR was used to examine the expression in leaves of five $N$. benthamiana homologs of pathogen- or PAMP-induced genes from Arabidopsis and tomato after inoculation with the type III secretion mutant DC3000 $h r c C$ mutant or the nonpathogen $P$. fluorescens. Expression of two of these genes, NbPti5 and NbGras2, was significantly increased by either DC3000AhrcC or P. fluorescens (Fig. 3B). We also developed primers and optimized PCR conditions to analyze the expression of $N b A C R E 31$, a gene previously shown to be induced by flg22 in $N$. benthamiana (Fig. 3B) (Heese et al. 2007).

\section{Callose deposition assay in $N$. benthamiana.}

Deposition of callose at the cell wall is a plant response to microbes that has been widely used as a marker for PTI in Arabidopsis and N. benthamiana (Adam and Somerville 1996; Hann and Rathjen 2007; Hauck et al. 2003). Arabidopsis plants with pmr4 (callose synthase) and nprl or pad4 mutations support higher growth of a $P$. syringae pv. phaseolicola strain expressing hopM $1_{P t o D C 3000}$, suggesting that formation of callose deposits can inhibit bacterial growth (Ham et al. 2007). We compared the timing of callose formation in Arabidopsis and $N$. benthamiana in response to buffer only $(5 \mathrm{mM}$ morpholineethanesulfonic acid [MES]), flg22, DC3000, or DC3000 $4 h r c Q U$ (Badel et al. 2006). In Arabidopsis, flg22 and DC3000 $\triangle \mathrm{hrc} Q U$ induced numerous callose deposits $6 \mathrm{~h}$ postinoculation (hpi), whereas buffer-only or wild-type DC3000 did not induce callose formation (Fig. 4A). At $12 \mathrm{hpi}$, DC3000 $4 h r c Q U$ induced formation of twofold more callose deposits than flg22, which probably reflects the action of numerous PAMPs present in this bacterium. Flg22 and DC3000 $\triangle h r c Q U$ induced callose formation to a similar degree in leaves of $N$. benthamiana, although it was not observable until later (at $24 \mathrm{hpi}$ ) than in Arabidopsis. As expected, neither bufferonly nor wild-type DC3000 caused callose formation in $N$. benthamiana (Fig. 4B).

These experiments revealed that callose deposition occurs in markedly different ways in Arabidopsis and N. benthamiana. First, flg22 and the type III secretion system (T3SS)deficient DC3000 strain induced callose formation much faster in Arabidopsis than in N. benthamiana. Second, the number of callose deposits induced by flg22 was approximately fivefold higher in Arabidopsis than in $N$. benthamiana. Third, the T3SS mutant induced twofold more callose deposits in Arabidopsis than did flg22 12 hpi, whereas flg22 and the T3SS mutant induced similar numbers of callose deposits in $N$. benthamiana. Together, these observations raise the possibility that the role of callose deposition might be fundamentally different in these two model plants and, in particular, are consistent with the possibility of greater importance of Fls2-mediated detection of flagellin in N. benthamiana, which lacks the EFR pattern recognition receptor for the EF-Tu PAMP (Zipfel et al. 2006). 
Development of a SlPti5::LUC reporter for assaying PTI in protoplasts of tomato and $N$. benthamiana.

Plant protoplasts have been used successfully as transient expression systems to dissect signal transduction pathways in response to specific PAMPs (Asai et al. 2002; He et al. 2006; Sheen 2001). One of the features of the Arabidopsis protoplast system is the use of luciferase (LUC) as a reporter to quantify activation of specific gene promoters (Asai et al. 2002). SIPti5 is a transcription factor that was identified as a Pto-interactor in a yeast two-hybrid library screen (Zhou et al. 1997). As shown above, the SlPti5 gene is strongly induced in leaves upon inoculation with the DC3000 $4 h r c Q U$ strain (Fig. 3A). The promoter region of Pti5 has been characterized and found to contain four $\mathrm{W}$ boxes, a $\mathrm{G}$ box, and a putative TGA1-binding site (H. Nakayashiki and G. Martin, unpublished). A 1-kb fragment encompassing this upstream region was fused to a LUC reporter gene to generate a SlPti5::LUC reporter construct.
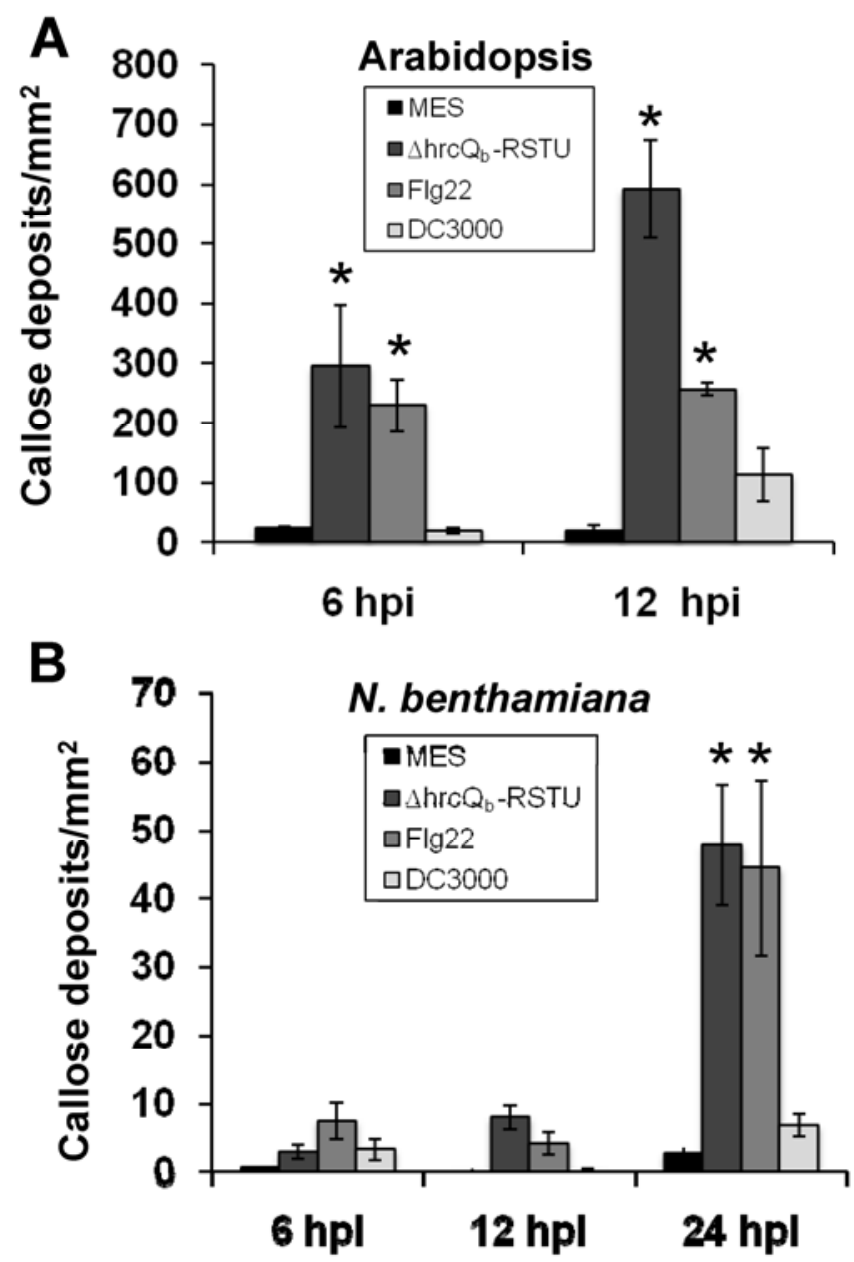

Fig. 4. Kinetics of callose deposition in Arabidopsis and Nicotiana benthamiana. Leaves of $\mathbf{A}$, Arabidopsis or $\mathbf{B}, N$. benthamiana were syringe infiltrated with flg22, DC3000, DC3000 $h r c Q_{b} R S T U$ (CUCPB5113), or buffer $\left(10 \mathrm{mM} \mathrm{MgCl}_{2}\right)$ and then assayed for callose deposition at the indicated times (hpi $=$ hours postinoculation) using aniline blue and epifluorescence microscopy. Callose deposits of 8.5 to $85 \mu \mathrm{m}$ in diameter were counted in captured images using CellProfiler software. Results shown are the mean number of callose deposits per square millimeter of leaf tissue and standard deviation from 16 microscopy fields from four samples for each treatment \pm standard error. Significantly different callose deposits compared with the mock inoculation based on comparisons of each pair using a Student's $t$ test $(P \leq 0.05)$ are indicated with an asterisk. The experiment was repeated two times for Arabidopsis and three times for $N$. benthamiana with similar results.
Tomato protoplasts were transformed with this reporter construct and a constitutively expressed $\beta$-glucuronidase (GUS) expression vector (Cauliflower mosaic virus [CaMV] 35S:: $G U S$ ) which served as a control for successful transformation. The protoplasts were then treated with buffer only or with 100 $\mathrm{nM}$ flg22 and SlPti5 promoter activity measured as a LUC/GUS ratio (GUS activity was unaffected by flg 22 treatment) (data not shown). The addition of flg22 increased SlPti5 promoter activity approximately sevenfold above the control (Fig. 5A). The T3SS effector AvrPto has been shown previously to suppress flg22-induced PTI responses in Arabidopsis (He et al. 2006), and we found that this effector also suppressed expression of the SIPti5:LUC reporter gene (Fig. 5A). We also tested the SIPti5::LUC construct for monitoring PTI in $N$. benthamiana protoplasts. SlPti5 promoter activity was induced approximately threefold in $N$. benthamiana protoplasts upon exposure to flg22 and approximately twofold in response to fungal chitin (Fig. 5B).
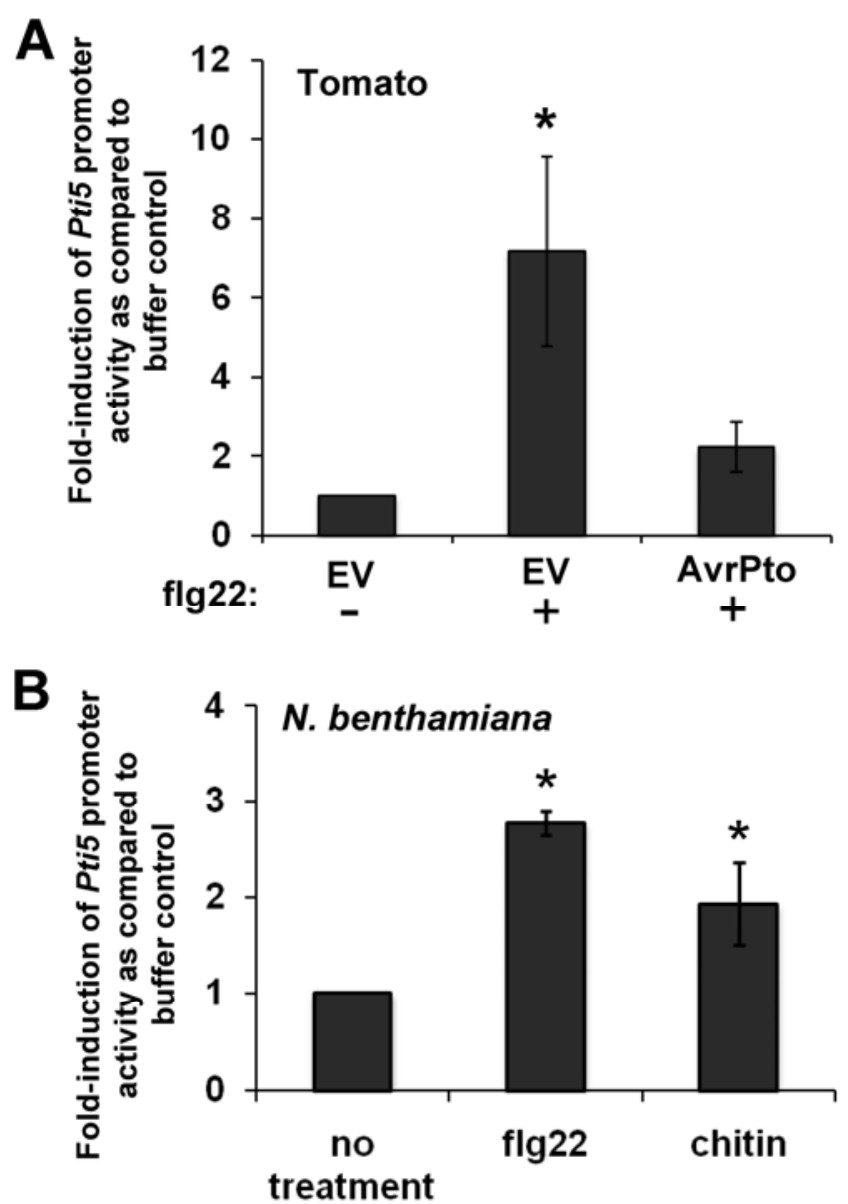

Fig. 5. Activation of SIPti5 promoter activity by pathogen-associated molecular patterns in tomato and Nicotiana benthamiana protoplasts. A, SlPti5 reporter gene is induced by flg 22 and AvrPto suppresses this induction in tomato protoplasts; EV = empty vector. Tomato Rio Grande-prf3 protoplasts were transfected with a construct containing the SlPti5 promoter with a luciferase (LUC) reporter ( $p P t i 5: L U C)$ and pCaMV35S: $\beta$ glucuronidase (GUS). Six hours after transfection, the protoplasts were treated with $100 \mathrm{nM}$ flg 22 for $3 \mathrm{~h}$. B, SlPti5 reporter gene is induced in $N$. benthamiana protoplasts. $N$. benthamiana protoplasts were transfected with pPti5::LUC and incubated for $6 \mathrm{~h}$ before being treated with either $100 \mathrm{nM}$ flg 22 or chitin at $50 \mu \mathrm{g} / \mathrm{ml}$ for $3 \mathrm{~h}$. Promoter activity in A and B was calculated as the LUC/GUS ratio and converted to fold-induction compared with buffer-only control samples, which were set at 1 . Error bars indicate \pm standard error (A, $n=4$ and $\mathrm{B}, n=3$ ). Significantly different level of promoter activity compared with the buffer-only control based on a Tukey highly significant difference test $(P \leq 0.05)$ is indicated with an asterisk. 
Optimization of a MAPK activation PTI assay for tomato and $N$. benthamiana protoplasts.

In Arabidopsis, the MAPK AtMPK3 and AtMPK6 have been found to be specifically activated by flg22 (Asai et al. 2002). These kinases were further used to study the activation of PTI in Arabidopsis by specific PAMPs as well as the suppression of certain components of PTI pathways by bacterial effector proteins (He et al. 2006). We relied on these studies to modify this assay for use in tomato protoplasts. Genes encoding the tomato homologs of AtMPK3 and AtMPK6, namely SlMpk1 and SlMpk3, respectively (Holley et al. 2003; Pedley and Martin 2004), were cloned into an expression vector, pTEX, and used for protoplast transformation. Similar to their Arabidopsis homologs, these MAPK were activated by flg22 and their activation was suppressed by $P$. syringae pv. tomato T3SS effector AvrPto (Fig. 6A). In addition, N. benthamiana homologs of AtMPK3 and AtMPK6, NbSIPK and NbWIPK, respectively (Sharma et al. 2003), were cloned into a protoplast expression vector, pJD301 (Promega Corp., Madison, WI, U.S.A.). These MAPK were also activated by flg22 (Fig. $6 \mathrm{~B})$ and other PAMPs, including PGN $(50 \mu \mathrm{g} / \mathrm{ml})$ and chitin $(50 \mu \mathrm{g} / \mathrm{ml})$ (Yeam et al. 2010) (data not shown).

In conclusion, we have presented a series of assays for measuring plant responses to PAMPs that have been optimized for tomato and $N$. benthamiana. Some of these assays have been developed in our laboratory while others were adapted and optimized from published protocols for Arabidopsis or $N$. benthamiana. We believe that these methods will be useful for the community studying molecular mechanisms underlying plant innate immunity. Our results also fur-
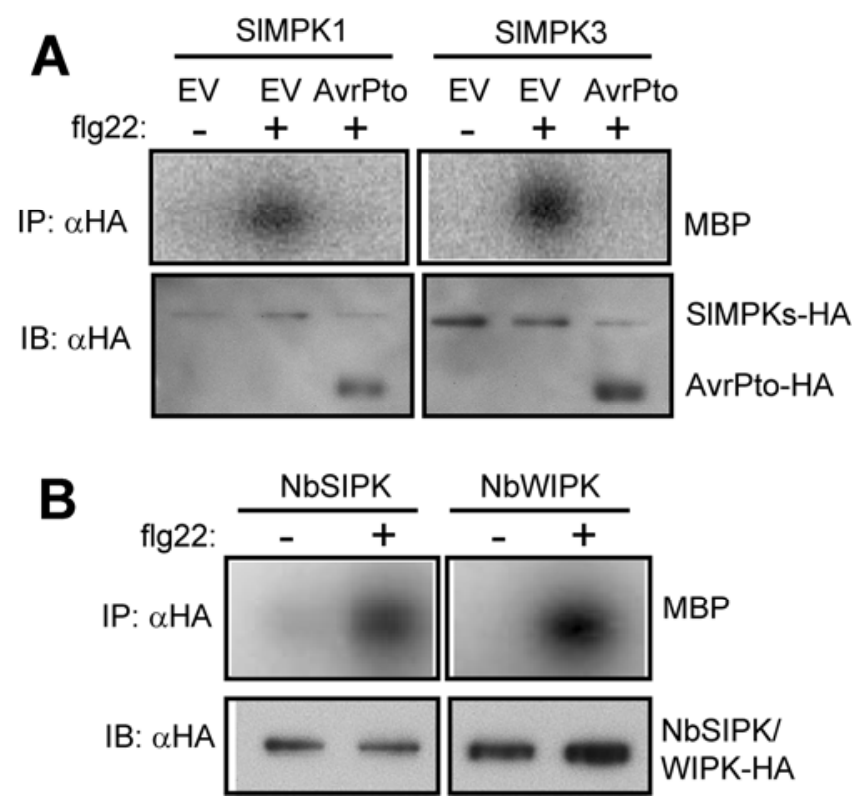

Fig. 6. Activation of mitogen-activated protein kinases (MAPK) by flg22 in tomato and Nicotiana benthamiana protoplasts. A, Activation of MAPK in tomato protoplasts by flg22 and suppression of MAPK activity by Pseudomonas syringae pv. tomato effector AvrPto. Hemagglutinin (HA)-tagged AvrPto or an empty vector (EV) control plasmid was co-expressed with HA-tagged SIMPK1 or SIMPK3 in tomato Rio Grande-prf3 protoplasts. Transfected protoplasts were incubated for $6 \mathrm{~h}$ before treatment with 100 $\mathrm{nM}$ flg22 for $10 \mathrm{~min}$. Anti-HA antibodies were used for the immunoprecipitation of SIMPK1/3 and AvrPto. In vitro kinase assay was used to detect kinase activity (upper panel). Lower panel shows a blot for protein expression of SIMPK1/3 and AvrPto using anti-HA antibodies. B, Activation of MAPK activity in $N$. benthamiana protoplasts. HA-tagged NbSIPK or NbWIPK was expressed in $N$. benthamiana protoplasts. Transfected protoplasts were subjected to similar treatments and assay as described above. ther demonstrate that, despite many similarities, there exist differences in the nature of PTI responses among different plant species. These differences highlight the need for the development and optimization of PTI assays for other plantmicrobe systems, especially those involving economically important crop species, such as members of the Poaceae (grass) and Fabaceae (legume) families.

\section{MATERIALS AND METHODS}

\section{Virulence assays.}

To prepare the bacterial inoculum, a lawn of Pseudomonas spp. was grown overnight at $30^{\circ} \mathrm{C}$ on King's medium B plates with the appropriate antibiotics. The cells were scraped from the plates into $10 \mathrm{mM} \mathrm{MgCl}_{2}$ and adjusted to the desired $\mathrm{CFU}$ per milliliter.

Seven-week-old $N$. benthamiana plants were used for the bacterial population assays. One day before the experiment, plants were transferred to a room with continuous light, $23^{\circ} \mathrm{C}$ temperature, and approximately $40 \%$ relative humidity (in our experience, these conditions are optimal, but researchers should test for themselves the conditions that work best in their facilities). P. fluorescens at $1 \times 10^{9} \mathrm{CFU} / \mathrm{ml}$ or $10 \mathrm{mM}$ $\mathrm{MgCl}_{2}$ was infiltrated with a needleless syringe into wellexpanded leaves of $N$. benthamiana and, $7 \mathrm{~h}$ later, DC3000

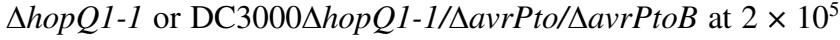
$\mathrm{CFU} / \mathrm{ml}$ were syringe infiltrated into an area overlapping the initial $P$. fluorescens infiltration. For tomato, PAMPs $(1 \mu \mathrm{M}$ flg22 or PGN at $100 \mu \mathrm{g} / \mathrm{ml}$ ) were infiltrated into wellexpanded leaves of 4-week-old plants (Rio Grande-prf3; RGprf3, Pto/Pto prf/prf). At $12 \mathrm{~h}$ after inoculation, the whole plants were vacuum infiltrated with DC3000 $\Delta a v r P t o / \Delta a v r P t o B$ $\left(5 \times 10^{4} \mathrm{CFU} / \mathrm{ml}\right)$. To assess bacterial populations, three 0.79 $\mathrm{cm}^{2}$ leaf discs were harvested from inoculated areas and ground in $1 \mathrm{ml}$ of $10 \mathrm{mM} \mathrm{MgCl}_{2}$, diluted, and plated to determine the CFU $/ \mathrm{cm}^{2}$ (Anderson et al. 2006). The flg22 peptide (TRLSSG LKINSAKDDAAGLQIA from DC3000; >85\% purity) was obtained from GenScript. The PGN, derived from S. aureus, was obtained from Sigma-Aldrich (no. 77140-25MG).

For enumeration of speck numbers, photographs of individual detached leaves from each treatment (4 days after inoculation) were analyzed using Adobe Photoshop CS4. Speck numbers were counted manually using the Count Tool. The leaf area was calculated for each leaf using the Analysis Tool. It is important to align a ruler to each leaf when taking the photographs in order to account for any differences in magnification that may occur during the analysis.

VIGS.

VIGS was performed as previously described (Velasquez et al. 2009). All N. benthamiana plants were kept in a growth chamber with a 16 -h day length and $50 \%$ relative humidity before they were used for the assays.

\section{Protoplast isolation and protoplast-based assays.}

Tomato RG-prf3 or $N$. benthamiana leaves, 3 to 4 weeks old, which were fully expanded and not too thick, were used for isolation of protoplasts. The abaxial side of leaflets was rubbed gently with Carborundum and serrated with a sharp razor blade without cutting through the leaflet. The leaflets were rinsed with water before placing their abaxial sides down in a petri dish containing $15 \mathrm{ml}$ of the enzyme solution (recipe below). After an overnight (for tomato) or 3-h (for $N$. benthamiana) incubation at $30^{\circ} \mathrm{C}$ in the dark, protoplasts were released from the leaflets by gently swirling the plate by hand. The mixture was poured through a $45-$ to $100-\mu \mathrm{m}$ sieve to collect protoplasts that were then divided $(7.5 \mathrm{ml})$ 
into two 15-ml culture tubes. Viable protoplasts were isolated by sucrose gradient centrifugation as follows. The protoplast mixture was gently overlaid with $1 \mathrm{ml}$ of W5 solution (recipe below) and centrifuged without mixing at $400 \times g$ for 3 min ( 0 brake and 0 acceleration). The layer containing viable green protoplasts was transferred to a new tube (the gradients are as follows, from top to bottom: W5, viable green protoplasts, brownish green protoplasts, and a pellet of dead protoplasts and cell debris). Viable protoplasts were washed once with fresh W5 and then allowed to recover on ice in fresh W5 for at least $1.5 \mathrm{~h}$ in the dark with good aeration (protoplasts in the solution were gently suspended every 15 min to prevent pellet formation). Protoplasts were quantified using a hemacytometer under a light microscope. After the incubation period, protoplasts were collected by centrifugation $(100 \times g$ for $1 \mathrm{~min})$ and resuspended in MMG buffer (recipe below) at a density of $2 \times 10^{5}$ protoplasts $/ \mathrm{ml}$. Protoplasts were maintained on ice (up to $3 \mathrm{~h}$ ). Polyethylene-glycol mediated transformation of protoplasts was performed as described by He and associates (2006) (or on the website of the Jen Sheen laboratory). Six hours after transformation, PAMP treatments were performed for $10 \mathrm{~min}$ (MAPK suppression assay) or $3 \mathrm{~h}$ (LUC assay) before collecting the protoplasts by centrifugation. The treated protoplasts were kept at $-80^{\circ} \mathrm{C}$ until use for the assays.

\section{Recipes.}

Protoplast isolation medium: $\mathrm{K} 3+0.4 \mathrm{M}$ sucrose $+1 \%$ cellulase $+0.15 \%$ macarozyme

For 1 liter: K3 (100 ml of stock I, $5 \mathrm{ml}$ of stock II, $2 \mathrm{ml}$ of stock III, $10 \mathrm{ml}$ of stock IV, and $10 \mathrm{ml}$ of stock V), $136.8 \mathrm{~g}$ of sucrose, $3 \mathrm{~g}$ of cellulase R10, and $1.5 \mathrm{~g}$ of macarozyme.

Stock I (1 liter): $1.5 \mathrm{~g}$ of $\mathrm{NaH}_{2} \mathrm{PO}_{4} \cdot 2 \mathrm{H}_{2} \mathrm{O}, 9.0 \mathrm{~g}$ of $\mathrm{CaCl}_{2}$ - $2 \mathrm{H}_{2} \mathrm{O}, 25 \mathrm{~g}$ of $\mathrm{KNO}_{3}, 2.5 \mathrm{~g}$ of $\mathrm{NH}_{4} \mathrm{NO}_{3}$, and $1.3 \mathrm{~g}$ of $\left(\mathrm{NH}_{4}\right)_{2} \mathrm{SO}_{4}$.

Stock II consisted of $1 \%$ EDTA ferric sodium salt.

Stock III (1 liter) consisted of $12.5 \mathrm{mg}$ of $\mathrm{CuSO}_{4} \cdot 7 \mathrm{H}_{2} \mathrm{O}$ and $12.5 \mathrm{mg}$ of $\mathrm{CoCl}_{2} \cdot 6 \mathrm{H}_{2} \mathrm{O}$.

Stock IV (1 liter) consisted of $75 \mathrm{mg}$ of KI, $1 \mathrm{~g}$ of $\mathrm{MnSO}_{4}$ - $\mathrm{H}_{2} \mathrm{O}, 200 \mathrm{mg}$ of $\mathrm{ZnSO}_{4} \cdot 7 \mathrm{H}_{2} \mathrm{O}, 300 \mathrm{mg}$ of $\mathrm{H}_{3} \mathrm{BO}_{3}, 25$ $\mathrm{mg}$ of $\mathrm{Na}_{2} \mathrm{MoO}_{4} \cdot 2 \mathrm{H}_{2} \mathrm{O}$, and $25 \mathrm{~g}$ of $\mathrm{MgSO}_{4} \cdot 7 \mathrm{H}_{2} \mathrm{O}$.

Stock V (1 liter) consisted of $1 \mathrm{~g}$ of Thiamine $\mathrm{HCl}, 100$ $\mathrm{mg}$ of nicotinic acid, $100 \mathrm{mg}$ of pyridoxine $\mathrm{HCl}, 10 \mathrm{~g}$ of m-inositol, and $25 \mathrm{~g}$ of xylose.

W5 (1 liter): $9.0 \mathrm{~g}$ of $\mathrm{NaCl}, 1.0 \mathrm{~g}$ of glucose, $18.4 \mathrm{~g}$ of $\mathrm{CaCl}_{2}$ $\cdot 2 \mathrm{H}_{2} \mathrm{O}$, and $0.4 \mathrm{~g}$ of $\mathrm{KCl}$.

$M M G$ buffer: $0.4 \mathrm{M}$ mannitol, $15 \mathrm{mM} \mathrm{MgCl}_{2}$, and $4 \mathrm{mM}$ MES (pH 5.7).

\section{Promoter reporter, MAPK, and AvrPto constructs.}

Each hemagglutinin-tagged SIMPK gene was expressed in protoplasts using the pTEX CaMV 35S promoter expression cassette. $\mathrm{NbSIPK/WIPK}$ and the AvrPto gene were expressed from an enhanced CaMV 35S promoter in vector pJD301 (Promega Corp.). In total, $10 \mu \mathrm{g}$ of pTEX::SlMPKs or $7 \mu \mathrm{g}$ of pJD301 plasmid was used in each transformation. Full-length SlPti5 promoter was subcloned into $p F R K 1:: L U C$ nos c vector using BamHI ( $\left.5^{\prime}\right)$ and $N c o I\left(3^{\prime}\right)$ sites, which remove the entire FRK 1 cassette. The recombinant pSIPti5::LUC nos c $(10 \mu \mathrm{g})$ was used in each transformation.

\section{MAPK assay.}

Activation and suppression of PAMP-induced MAPK in tomato and $N$. benthamiana protoplasts was performed as described by $\mathrm{He}$ and associates (2006). The amount of flg22 used was $100 \mathrm{nM}$.

\section{LUC assay.}

LUC activity assays were performed as described by He and associates (2006) using the Luciferase Assay System kit (Promega Corp.). LUC activity was calculated as the ratio of LUC/GUS.

\section{Callose deposition assay.}

Callose deposition assays for Arabidopsis and N. benthamiana were modified as follows from previously described procedures (Ham et al. 2007; Hann and Rathjen 2007; Hauck et al. 2003). Leaves of 6- and 8-week-old N. benthamiana and Arabidopsis ecotype Columbia plants, respectively, were infiltrated with $40 \mu \mathrm{M}$ flg22 or a bacterial suspension of $2.2 \times 10^{8}$ $\mathrm{CFU} / \mathrm{ml}$ with a needleless syringe. After 6,12 , and $24 \mathrm{~h}$, leaf disks from infiltrated areas were excised with a cork borer from Arabidopsis ( $5 \mathrm{~mm}$ in diameter) and N. benthamiana (10 $\mathrm{mm}$ in diameter). The collected leaf disks were placed in wells of a 12-well microtiter plate containing $2 \mathrm{ml}$ of $95 \%$ ethanol and then incubated at $37^{\circ} \mathrm{C}$ until the leaf disks were cleared of chlorophyll, with the ethanol being replaced as necessary until the clearing was complete. The incubation time for leaf clearing was $3 \mathrm{~h}$ for Arabidopsis and $6 \mathrm{~h}$ for $N$. benthamiana. The cleared leaf disks were washed two times with $70 \%$ ethanol and then three times with distilled water. The leaf disks were then placed in the wells of a 12 -well plate and immersed in $1 \%$ aniline blue in $150 \mathrm{mM} \mathrm{K} \mathrm{HPO}_{4}(\mathrm{pH} 9.5 / \mathrm{KOH})$ and incubated in the dark $30 \mathrm{~min}$ for Arabidopsis and $1 \mathrm{~h}$ for $N$. benthamiana. The stained leaf disks were mounted with $60 \%$ glycerol on glass slides and observed from the adaxial surface of the disk by epifluorescence microscopy using ultraviolet light. Images of $1-\mathrm{mm}^{2}$ microscopy fields, avoiding areas close to wounds generated by inoculation or by sample excision, were captured using an Olympus digital camera and its software (DP2-BSW). The numbers of callose deposits of 8.5 to $85 \mu \mathrm{m}$ in diameter, detected by aniline blue fluorescence, were counted in complete fields using CellProfiler cell image analysis software.

\section{qRT-PCR for marker gene expression.}

Four-week-old RG-prf3 tomato plants were vacuum infiltrated with a suspension of DC3000 $4 h r c Q U$ at $2 \times 10^{8}$ $\mathrm{CFU} / \mathrm{ml}$ in $10 \mathrm{mM} \mathrm{MgCl} 2$ containing $0.002 \%$ Silwet or $P$. fluorescens at $1 \times 10^{9} \mathrm{CFU} / \mathrm{ml}$, or mock inoculated with $10 \mathrm{mM}$ $\mathrm{MgCl}_{2}$ containing $0.002 \%$ Silwet. Five-week-old $N$. benthamiana plants were syringe infiltrated on one half of a well-expanded leaf with a suspension of either DC30000 $4 h r c C$ or $P$. fluorescens at $2 \times 10^{8} \mathrm{CFU} / \mathrm{ml}$ in $10 \mathrm{mM} \mathrm{MgCl}$. As a control, $10 \mathrm{mM} \mathrm{MgCl}$ was syringe infiltrated on the other half of the leaf. Leaf tissue was harvested at $6 \mathrm{~h}$ after infiltration for tomato and $N$. benthamiana. Total RNA was isolated using the RNeasy plant mini kit (Qiagen, Valencia, CA, U.S.A.) and treated with RQ1 DNase (Promega Corp.), followed by column purification using the RNeasy mini kit (Qiagen). One microgram was used to prepare cDNA using Superscript III and oligo dT primer (Invitrogen, Carlsbad, CA, U.S.A.). qRT-PCR was performed using 150 to $400 \mathrm{nM}$ sequence-specific primers and SYBR Green (Applied Biosystems Inc, Foster City, CA, U.S.A.) with the ABI Prism 7900 HT Sequence Detection System. Primers were designed using the PrimerQuest software of IDT (Integrated DNA Technologies, Coralville, IA, U.S.A.). The efficiency of all primer pairs used was calculated to be $\geq 1.8$ using the formula $10^{(-1 / \text { slope })}$ (Pfaffl 2001).

A mock cDNA reaction lacking Superscript III was performed for each RNA sample and checked in a qRT-PCR reaction with ATPase control primers to check for DNA contamination. Cycling conditions during qRT-PCR were $50^{\circ} \mathrm{C}$ for 2 $\min , 95^{\circ} \mathrm{C}$ for $10 \mathrm{~min}$, and 40 cycles of $95^{\circ} \mathrm{C}$ for $30 \mathrm{~s}$ and $60^{\circ} \mathrm{C}$ 
for $1 \mathrm{~min}$. Each reaction was performed in triplicate. Dissociation curve analysis was performed at the end of each run to ensure that unique products were amplified. Data was normalized to the ATPase control gene. Fold-induction of gene expression was calculated using the $2^{-\Delta \Delta \mathrm{Ct}}$ method (Pfaffl 2001). The $\Delta \mathrm{Ct}$ (cycle threshold) values for gene-of-interest (bufferpathogen) and the ATPase control (buffer-pathogen) were calculated for all samples and used to compute the significance of induction levels observed. A pairwise Student's $t$ test was performed to obtain the $P$ values indicated in the figure. The plasmids and bacterial strains described in this article are available as a consolidated "Solanaceae PTI assay kit".

\section{ACKNOWLEDGMENTS}

We thank S. Despa, Cornell University Statistical Consulting Unit, for help with statistical analysis and J. Munkvold for critical comments on the manuscript. This work was supported by funding from the National Science Foundation (NSF) (IOB-0841807) to G. B. Martin, NSF (DBI0605059) to G. B. Martin and A. Collmer, United States Department of Agriculture (USDA) National Institute of Food and Agriculture (201065108-20503) to G. B. Martin, and the USDA Binational Agricultural Research \& Development Fund (IS-4159-08C) to G. B. Martin.

\section{LITERATURE CITED}

Adam, L., and Somerville, S. C. 1996. Genetic characterization of five powdery mildew disease resistance loci in Arabidopsis thaliana. Plant J. 9:341-356.

Anderson, J. C., Pascuzzi, P. E., Xiao, F., Sessa, G., and Martin, G. B. 2006. Host-mediated phosphorylation of type III effector AvrPto promotes Pseudomonas virulence and avirulence in tomato. Plant Cell 18:502-514.

Asai, S., Ohta, K., and Yoshioka, H. 2008. MAPK signaling regulates nitric oxide and NADPH oxidase-dependent oxidative bursts in Nicotiana benthamiana. Plant Cell 20:1390-1406.

Asai, T., Tena, G., Plotnikova, J., Willmann, M. R., Chiu, W. L., GomezGomez, L., Boller, T., Ausubel, F. M., and Sheen, J. 2002. MAP kinase signalling cascade in Arabidopsis innate immunity. Nature 415:977-983.

Ausubel, F. M. 2005. Are innate immune signaling pathways in plants and animals conserved? Nat. Immunol. 6:973-979.

Badel, J. L., Shimizu, R., Oh, H. S., and Collmer, A. 2006. A Pseudomonas syringae pv. tomato avrE1/hopM1 mutant is severely reduced in growth and lesion formation in tomato. Mol. Plant-Microbe Interact. 19:99-111.

Boller, T., and Felix, G. 2009. A renaissance of elicitors: Perception of microbe-associated molecular patterns and danger signals by pattern-recognition receptors. Annu. Rev. Plant Biol. 60:379-406.

Chakravarthy, S., Velasquez, A. C., and Martin, G. B. 2009. Assay for pathogen-associated molecular pattern (PAMP)-triggered immunity (PTI) in plants. J. Visualiz. Exper. 31. www.jove.com/index/Details.stp?ID=1442. doi: 1410.3791/1442. Published online

Chakravarthy, S., Velásquez, A., Ekengren, S., Collmer, A., and Martin, G. B. Identification of Nicotiana benthamiana genes involved in PAMPtriggered immunity Mol. Plant-Microbe Interact. 23: 715-726.

Chinchilla, D., Bauer, Z., Regenass, M., Boller, T., and Felix, G. 2006. The Arabidopsis receptor kinase FLS2 binds flg22 and determines the specificity of flagellin perception. Plant Cell 18:465-476.

Erbs, G., Silipo, A., Aslam, S., De Castro, C., Liparoti, V., Flagiello, A., Pucci, P., Lanzetta, R., Parrilli, M., Molinaro, A., Newman, M. A., and Cooper, R. M. 2008. Peptidoglycan and muropeptides from pathogens Agrobacterium and Xanthomonas elicit plant innate immunity: Structure and activity. Chem. Biol. 15:438-448.

Felix, G., Duran, J. D., Volko, S., and Boller, T. 1999. Plants have a sensitive perception system for the most conserved domain of bacterial flagellin. Plant J. 18:265-276.

Gomez-Gomez, L., and Boller, T. 2000. FLS2: An LRR receptor-like kinase involved in the perception of the bacterial elicitor flagellin in Arabidopsis. Mol. Cell 5:1003-1011.

Goodin, M. M., Zaitlin, D., Naidu, R. A., and Lommel, S. A. 2008. Nicotiana benthamiana: Its history and future as a model for plant-pathogen interactions. Mol. Plant-Microbe Interact. 21:1015-1026.

Gust, A. A., Biswas, R., Lenz, H. D., Rauhut, T., Ranf, S., Kemmerling, B., Gotz, F., Glawischnig, E., Lee, J., Felix, G., and Nurnberger, T. 2007. Bacteria-derived peptidoglycans constitute pathogen-associated molecular patterns triggering innate immunity in Arabidopsis. J. Biol.
Chem. 282:32338-32348.

Ham, J. H., Kim, M. G., Lee, S. Y., and Mackey, D. 2007. Layered basal defenses underlie non-host resistance of Arabidopsis to Pseudomonas syringae pv. phaseolicola. Plant J. 51:604-616.

Hann, D. R., and Rathjen, J. P. 2007. Early events in the pathogenicity of Pseudomonas syringae on Nicotiana benthamiana. Plant J. 49:607-618.

Hauck, P., Thilmony, R., and He, S. Y. 2003. A Pseudomonas syringae type III effector suppresses cell wall-based extracellular defense in susceptible Arabidopsis plants. Proc. Natl. Acad. Sci. U.S.A. 100:85778582 .

He, P., Shan, L., Lin, N. C., Martin, G. B., Kemmerling, B., Nurnberger, T., and Sheen, J. 2006. Specific bacterial suppressors of MAMP signaling upstream of MAPKKK in Arabidopsis innate immunity. Cell $125: 563-575$

Heese, A., Hann, D. R., Gimenez-Ibanez, S., Jones, A. M., He, K., Li, J., Schroeder, J. I., Peck, S. C., and Rathjen, J. P. 2007. The receptor-like kinase SERK3/BAK1 is a central regulator of innate immunity in plants. Proc. Natl. Acad. Sci. U.S.A. 104:12217-12222.

Holley, S. R., Yalamanchili, R. D., Moura, D. S., Ryan, C. A., and Stratmann, J. W. 2003. Convergence of signaling pathways induced by systemin, oligosaccharide elicitors, and ultraviolet-B radiation at the level of mitogen-activated protein kinases in Lycopersicon peruvianum suspension-cultured cells. Plant Physiol. 132:1728-1738.

Kim, J.-G., Li, X., Roden, J. A., Taylor, K. W., Aakre, C. D., Su, B., Lalonde, S., Kirik, A., Chen, Y., Baranage, G., McLane, H., Martin, G. B., and Mudgett, M. B. 2009. Xanthomonas T3S Effector XopN suppresses PAMP-triggered immunity and interacts with a tomato atypical receptor-like kinase and TFT1. Plant Cell 21:19.

Klement, Z., Bozso, Z., Kecskes, M. L., Besenyei, E., Arnold, C., and Ott, P. G. 2003. Local early induced resistance of plants as the first line of defence against bacteria. Pest Manage. Sci. 59:465-474.

Kunze, G., Zipfel, C., Robatzek, S., Niehaus, K., Boller, T., and Felix, G. 2004. The $\mathrm{N}$ terminus of bacterial elongation factor $\mathrm{Tu}$ elicits innate immunity in Arabidopsis plants. Plant Cell 16:3496-3507.

Kvitko, B. H., Park, D. H., Velasquez, A. C., Wei, C. F., Russell, A. B., Martin, G. B., Schneider, D. J., and Collmer, A. 2009. Deletions in the repertoire of Pseudomonas syringae pv. tomato DC3000 type III secretion effector genes reveal functional overlap among effectors. PLoS Pathog. 5:e1000388.

Lin, N.-C., and Martin, G. B. 2005. An avrPto/avrPtoB mutant of Pseudomonas syringae pv. tomato DC3000 does not elicit Pto-mediated resistance is less virulent on tomato. Mol. Plant-Microbe Interact. 18:43-51.

Lu, D., Wu, S., Gao, X., Zhang, Y., Shan, L., and He, P. 2010. A receptorlike cytoplasmic kinase, BIK1, associates with a flagellin receptor complex to initiate plant innate immunity. Proc. Natl. Acad. Sci. U.S.A. 107:496-501

Mayrose, M., Ekengren, S. K., Melech-Bonfil, S., Martin, G. B., and Sessa, G. 2006. A novel link between tomato GRAS genes, plant disease resistance and mechanical stress response. Mol. Plant Pathol. 7:593-604.

Meindl, T., Boller, T., and Felix, G. 2000. The bacterial elicitor flagellin activates its receptor in tomato cells according to the address-message concept. Plant Cell 12:1783-1794.

Mishina, T. E., and Zeier, J. 2007. Pathogen-associated molecular pattern recognition rather than development of tissue necrosis contributes to bacterial induction of systemic acquired resistance in Arabidopsis. Plant J. 50:500-513.

Navarro, L., Zipfel, C., Rowland, O., Keller, I., Robatzek, S., Boller, T., and Jones, J. D. 2004. The transcriptional innate immune response to flg22. Interplay and overlap with Avr gene-dependent defense responses and bacterial pathogenesis. Plant Physiol. 135:1113-1128.

Newman, M. A., von Roepenack-Lahaye, E., Parr, A., Daniels, M. J., and Dow, J. M. 2002. Prior exposure to lipopolysaccharide potentiates expression of plant defenses in response to bacteria. Plant J. 29:487-495.

Oh, H.-S., and Collmer, A. 2005. Basal resistance against bacteria in Nicotiana benthamiana leaves is accompanied by reduced vascular staining and suppressed by multiple Pseudomonas syringae type III secretion system effector proteins. Plant J. 44:348-359.

Oh, H.-S., Park, D.-H., and Collmer, A. Components of the Pseudomonas syringae type III secretion system can elicit and suppress plant innate immunity. Mol. Plant-Microbe Interact. 23:727-739.

Olmstead, R. G., Bohs, L., Migid, H. A., Santiago-Valentin, E., Garcia, V. F., and Collier, S. M. 2008. A molecular phylogeny of the Solanaceae. Taxon 57:1159-1181.

Pedley, K. F., and Martin, G. B. 2004. Identification of MAPKs and their possible MAPK kinase activators involved in the Pto-mediated defense response of tomato. J. Biol. Chem. 279:49229-49235.

Pfaffl, M. W. 2001. A new mathematical model for relative quantification in real-time RT-PCR. Nucleic Acids Res. 29:e45.

Shan, L., He, P., Li, J., Heese, A., Peck, S. C., Nurnberger, T., Martin, G. 
B., and Sheen, J. 2008. Bacterial effectors target the common signaling partner BAK1 to disrupt multiple MAMP receptor-signaling complexes and impede plant immunity. Cell Host Microbe 4:17-27.

Sharma, P. C., Ito, A., Shimizu, T., Terauchi, R., Kamoun, S., and Saitoh, H. 2003. Virus-induced silencing of WIPK and SIPK genes reduces resistance to a bacterial pathogen, but has no effect on the INF1-induced hypersensitive response (HR) in Nicotiana benthamiana. Mol. Genet. Genomics 269:583-591.

Sheen, J. 2001. Signal transduction in maize and Arabidopsis mesophyll protoplasts. Plant Physiol. 127:1466-1475.

Thara, V. K., Tang, X., Gu, Y. Q., Martin, G. B., and Zhou, J. M. 1999. Pseudomonas syringae pv. tomato induces the expression of tomato EREBP-like genes Pti4 and Pti5 independent of ethylene, salicylate and jasmonate. Plant J. 20:475-483.

Udvardi, M. K., Czechowski, T., and Scheible, W. R. 2008. Eleven golden rules of quantitative RT-PCR. Plant Cell 20:1736-1737.

Velasquez, A. C., Chakravarthy, S., and Martin, G. B. 2009. Virus-induced gene silencing (VIGS) in Nicotiana benthamiana and tomato. J. Visualiz. Exper. 28. www.jove.com/index/Details.stp?ID=1292. doi: $1210.3791 / 1292$.

Wei, C. F., Kvitko, B. H., Shimizu, R., Crabill, E., Alfano, J. R., Lin, N. C., Martin, G. B., Huang, H. C., and Collmer, A. 2007. A Pseudomonas syringae pv. tomato DC3000 mutant lacking the type III effector HopQ1-1 is able to cause disease in the model plant Nicotiana benthamiana. Plant J. 51:32-46.

Yeam, I., Nguyen, H. P., and Martin, G. B. 2010. Phosphorylation of the Pseudomonas syringae effector AvrPto is required for FLS2/BAK1- independent virulence activity and recognition by tobacco. Plant J. 61:16-24.

Zhang, X., Chen, S., Mengiste, T., Zhang, Y., and Zhou, J. (2010). Receptorlike cytoplasmic kinases integrate signaling from multiple plant immune receptors and are targeted by a Pseudomonas syringae effector. Cell Host Microbe 7:290-301.

Zhou, J., Tang, X., and Martin, G. B. 1997. The Pto kinase conferring resistance to tomato bacterial speck disease interacts with proteins that bind a cis-element of pathogenesis-related genes. EMBO (Eur. Mol. Biol. Organ.) J. 16:3207-3218.

Zipfel, C., Robatzek, S., Navarro, L., Oakeley, E. J., Jones, J. D., Felix, G., and Boller, T. 2004. Bacterial disease resistance in Arabidopsis through flagellin perception. Nature 428:764-767.

Zipfel, C., Kunze, G., Chinchilla, D., Caniard, A., Jones, J. D., Boller, T., and Felix, G. 2006. Perception of the bacterial PAMP EF-Tu by the receptor EFR restricts agrobacterium-mediated transformation. Cell $125: 749-760$

\section{AUTHOR-RECOMMENDED INTERNET RESOURCES}

CellProfiler, cell image analysis software: www.cellprofiler.org GenScript website: www.genscript.com

SOL Genomics Network (SGN): solgenomics.net

Sheen Lab, Massachusetts General Hospital and Harvard Medical School: genetics.mgh.harvard.edu/sheenweb

Tomato Genetics Resource Center: tgrc.ucdavis.edu 